\title{
Development and Application of a Sensitive, High Precision Weighing Lysimeter for use in Greenhouses
}

\author{
J. Mejuer*; G. P. A. Bot †; C. Stanghfillinił; A. J. Udink ten Cath†
}

\begin{abstract}
A high precision weighing lysimeter for measuring evapotranspiration in greenhouses was developed. The instrument has a measurement of sensitivity of one part in $10^{6}$, that is one order of magnitude better than any other so far described in the literature. With it, evaporation rates in a greenhouse, even at night, can be measured on a one minute time scale. Development and construction of the instrument are described and measurements of the transpiration of a tomato crop in a greenhouse are used to demonstrate its capabilities.
\end{abstract}

\section{Introduction}

In horticultural production in greenhouses, energy consumption during cold periods is a major cost-factor, especially in northern latitudes, but also in southern regions with large outdoor temperature fluctuations. In the energy balance of the greenhouse, the energy from the heating system and from solar radiation are the major sources, while evapotranspiration (ET) is an important sink. Therefore, a correct evaluation of ET under various indoor climatic conditions is necessary for any energy saving strategy,,$^{12}$ simulation study, ${ }^{3}$ or model studies based on energy and vapour balances. ${ }^{3,4,5}$ ET can be expressed as water loss $(\mathrm{mm} / \mathrm{s})$ or weight loss $\left(\mathrm{g} / \mathrm{m}^{2} \mathrm{~s}\right)$, which can easily be related to evaporation energy $\left(\mathrm{W} / \mathrm{m}^{2}\right)$.

In such studies, the response of ET to varying environmental conditions must be known on a time scale of minutes. These models seek a better insight into the greenhouse climate, the effect of different insulating systems (thermal screens, double layered glass or plastic covers). They may also be linked to crop growth control strategies as described by Bot. ${ }^{4}$ In the "speaking plant" approach (Udink ten Cate et al.," literature survey by Udink ten Cate"), they are required to use computers to relate direct measurements of plant parameters to climate setpoints in control strategies. Measurements of instantaneous ET and of water status as plant parameters are of special interest in this context, as discussed for example by Hashimoto, ${ }^{\mathbf{8}}$ Hopmans ${ }^{\mathbf{9}}$ and Schurer et al. ${ }^{10}$

Evaporation rates in greenhouses are known to be low. Overall ET during a full night is given by De Graaf ${ }^{1}$ as $0.4 \mathrm{~mm}$. When meaningful information on a time scale of minutes is needed, a resolution of $5 \cdot 10^{-5} \mathrm{~mm}\left(0.05 \mathrm{~g} / \mathrm{m}^{2}\right.$ ground area $)$ has to be achieved. When a minimum number of plants is weighed with the lysimeter, say five with a typical plant density of two plants $/ \mathrm{m}^{2}$, $100 \mathrm{~kg}$ of load capacity is needed for plants grown on artificial substrates and about $1000 \mathrm{~kg}$ for soil. This implies a need for measurement sensitivities of about $10^{-6}$ and $10^{-7}$, respectively (that is one part in $10^{6}$ and $10^{7}$ respectively). Lysimeter installations with accuracies in the order of $10^{-5}$ are described in the literature ${ }^{12-15}$ all referring to large outdoor installations. Van Bavel and Myers ${ }^{13}$ show some evaporative flux data, taken on a time basis of 5 minutes, while 15 minute values can be inferred from data produced by Ritchie and Burnett. ${ }^{15}$ Weighable lysimeter installations used in greenhouse applications are reported to have much lower accuracy. ${ }^{16-22}$ In none of these papers are ET figures produced for time intervals shorter than one hour.

\footnotetext{
*Twente University of Technology, Enschede, The Netherlands

†Agricultural University Wageningen, The Netherlands

¥Institute of Agricultural Engineering (IMAG) Wageningen

Received 9 January 1984; accepted in revised form I0 January 1985
} 


\section{NOTATION}

$A_{1}$ area of the flapper-nozzle

$A_{2}$ area of the pneumatic balance

$D$ diameter

E Young modulus

ET evapotranspiration

$F$ force

$F^{\prime}$ balance force

$K_{\mathrm{d}}$ diaphragm constant

$K_{\mathrm{n}}$ nozzle constant

$L$ length

$R$ radius

$R_{\mathrm{g}}$ global solar radiation

$R_{\mathrm{n}}$ net radiation

$T$ temperature

$T_{\mathrm{h}}$ temperature of heating pipes

$T_{\mathrm{a}}$ temperature of air

$U$ voltage

$b$ membrane width

$d$ diameter

$f_{\mathrm{d}}$ drag coefficient

$m$ mass

$m_{n}$ mean value $m_{n}=\frac{1}{n} \sum m_{i}$

$m_{\mathrm{p}}$ mass of plants

$m_{\mathrm{r}}$ mass of reference weight

$m_{\mathrm{o}}$ mass of moving (lysimeter) parts

$n$ number of samples

$p$ pressure

$p_{\text {atm }}$ atmospheric pressure

$p_{\mathrm{p}}$ pressure at plant side

$p_{\mathrm{r}}$ pressure at reference side

$t$ time

$v$ velocity

$w$ width

$x$ displacement

$y$ displacement

$a$ coefficient of thermal expansion

$\beta$ relative damping

$\eta$ viscosity

$\theta$ clamping angle

$\lambda$ temp. coefficient of Young modulus

$v \quad$ Poisson constant

$\rho$ specific mass

$\sigma$ tension

$\sigma_{\mathrm{n}}$ standard deviation (of $m_{\mathrm{n}}$ )

$\tau$ time constant

$\omega$ angular velocity 

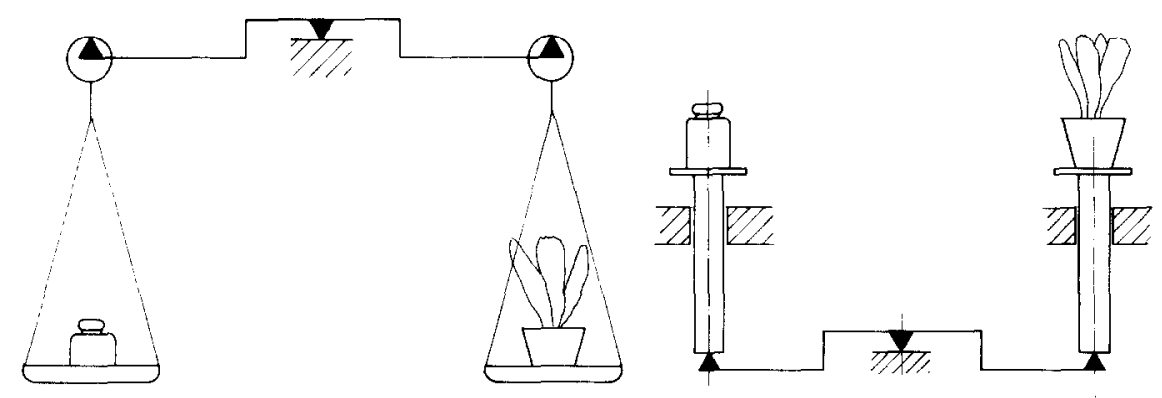

Fig. 1. Simple type of balance: construction below ground level (right) requires additional bearings but friction can be reduced by using air bearings

The development of a lysimeter with a sensitivity onc order of magnitude better than any previously available device is reported in this paper, together with test results and field experiments. The new instrument allows experiments to be performed with perfectly normal plants growing in the same conditions and with the same growth rate as any other plant in the greenhouse.

\section{Development and construction}

\subsection{Requirements}

As shown by Tegelaar and van der Wal, ${ }^{23}$ it is possible to obtain a resolution of $1 \mathrm{~g}$ within a range of $500 \mathrm{~g}$ with a simple type of balance developed for a maximum load of $25 \mathrm{~kg}$ (Fig. 1, left). Unfortunately, this laboratory accuracy could not be reproduced in greenhouse conditions. Variations in temperature, especially when caused by direct sunshine, are found to be a troublesome source of thermal errors. These errors seem to be inherent for constructions above ground level. Discussions with horticultural scientists have resulted in a list of requirements:

(1) no disturbance of plant row configuration;

(2) minimal effects on light and air movement around the plants;

(3) maximum load of at least $100 \mathrm{~kg}$;

(4) evaporation rates down to $0 \cdot 25 \mathrm{~g} / \mathrm{min}$ should be measurable;

(5) shortest time interval of measurements $30 \mathrm{~s}$;

(6) accuracy better than $5 \%$ in evaporation rate;

(7) measurement range up to $3 \mathrm{~kg}$;

(8) maximum moment on scales $100 \mathrm{Nm}$;

(9) automatic recording of the measured data;

(10) instrumentation up to $100 \mathrm{~m}$ distance;

(11) ambient temperature range 10 to $50^{\circ} \mathrm{C}$;

(12) relative humidity 20 to $100 \%$;

(13) proof against water, condensation, moulds and insects;

(14) transportable after each culture.

The necessary sensitivity (defined as the smallest value which can be detected) and accuracy can be found from the listed requirements. For technical and economic reasons, the ultimate accuracy of successive readings are limited to $0.1 \mathrm{~g}$, thus requiring a longer time interval to measure the slowest evaporation at the required accuracy. On a total load of $100 \mathrm{~kg}$, this implies a relative accuracy of $10^{-6}$, and even for the best analytical balances this is difficult to achieve. ${ }^{24-26}$

\subsection{General layout}

From requirement (2), and to prevent thermal errors, it was decided to install the instrument below ground level. This requires additional bearings to balance the load and introduces more 


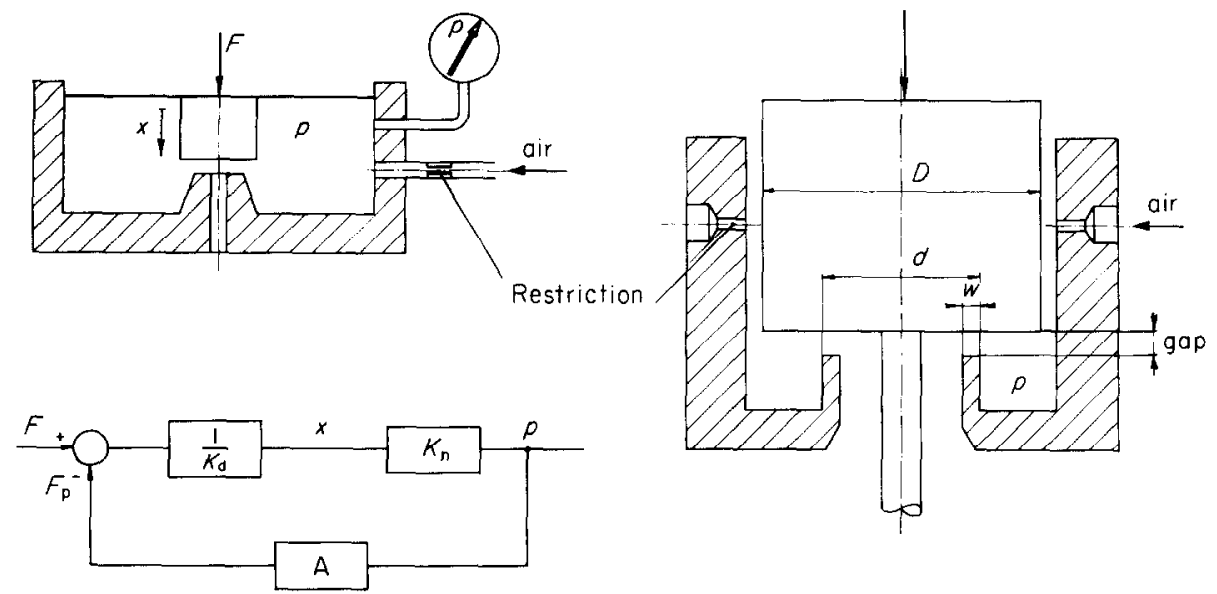

Fig. 2. Flapper-nozzle systems. (Left) A common type with block diagram, (right) the modified lysimeter type

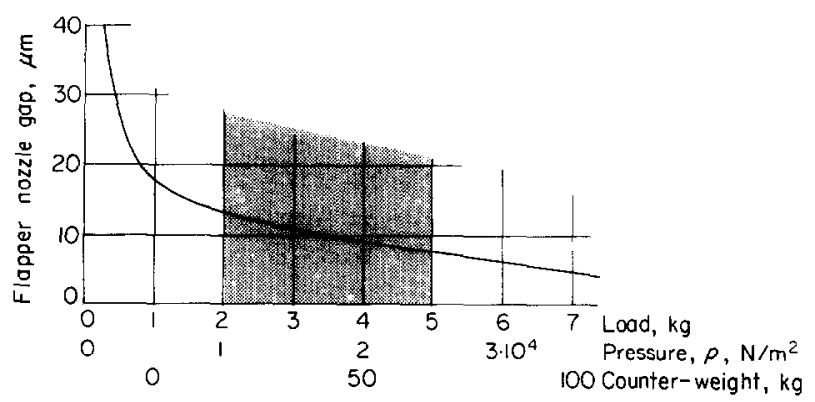

Fig. 3. The gap between fapper and nozzle as function of pressure or load

friction, but this can be decreased by using air bearings (Fig. l, right). When using air, a logical following stcp is to install a flapper-nozzle load cell at the plant side, in order to have a continuous signal proportional to the mass difference between the plant and reference weight sides. A common type of flapper-nozzle transducer used as a high gain amplifier in a servo-loop, is shown in Fig. 2. (see also Appendix A1). The flapper-nozzle characteristic, gap versus pressure or load, as measured for our modified type is shown in Fig. 3. It shows a nearly constant value of the nozzle constant $K_{\mathrm{n}}$ within a load range of 2 to $5 \mathrm{~kg}$ which has been chosen as the working range. The effective area $A_{1}$ (Fig. 2) is given by:

$$
A_{1}=\frac{\pi}{4}\left[D^{2}-(d-w)^{2}\right]
$$

While the use of air bearings solved the problem of additional friction, friction at the pivot points remained. In the final design, the balance arms (which are usually a source of errors) and the pivot points were eliminated completely (Fig. 4). This was done by coupling the reference and plant weights by balancing forces, which do not involve displacement, by including a second servo system on the reference side (Fig. 4). The air enters the system through the orifices of the air bearings (A) (Appendix A2) with a pressure of 5 bar. A part of the air enters the flapper-nozzle chamber (B), where the pressure is controlled by the gap (see also Fig. 2). This pressure $p_{\mathrm{r}}$ acts on the annular surface $\left(A_{1}\right)$ and, at the same time, on the lower surface $\left(A_{2}\right)$ of the disk (C) with a force $F^{\prime}$ as given at the counterweight scale of $F i g .3$. The same pressure $p_{\mathrm{r}}$ and hence force $F^{\prime}$ acts 


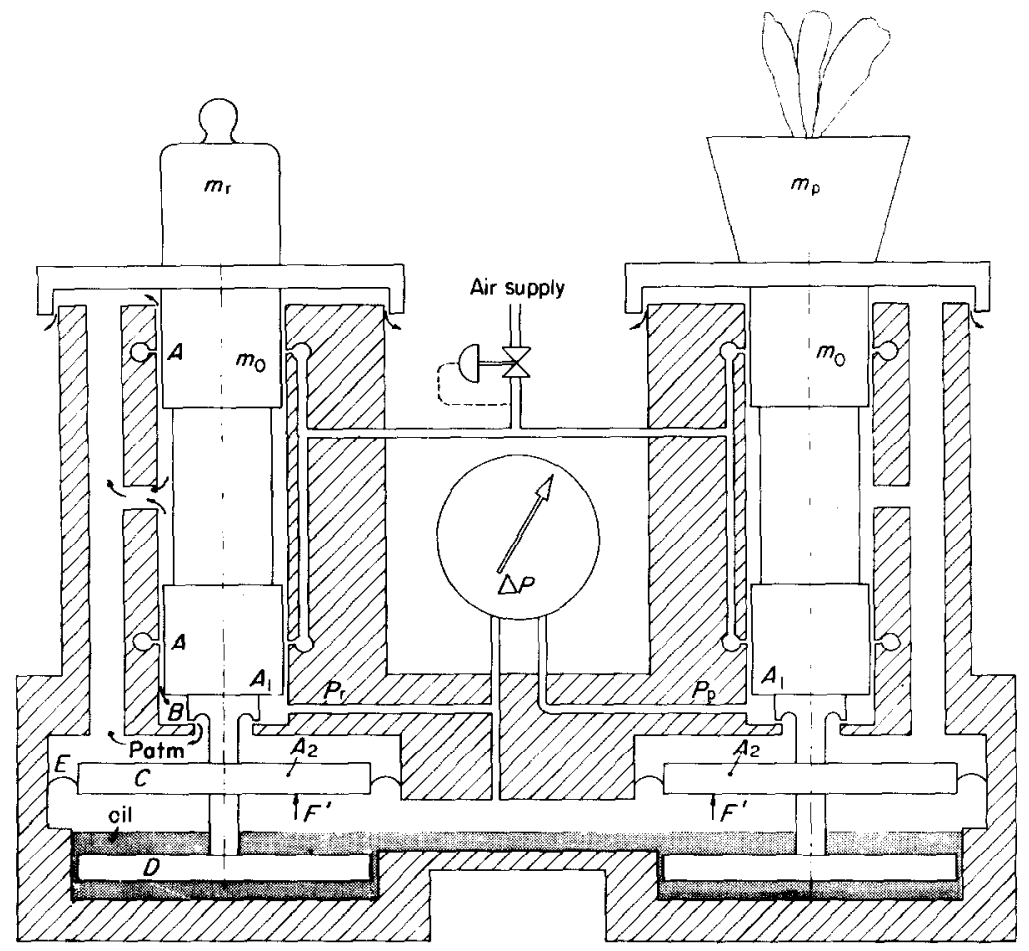

Fig. 4. Schematic design of the lysimeter. The symmetric design reduces errors due to temperature, atmospheric pressure, etc

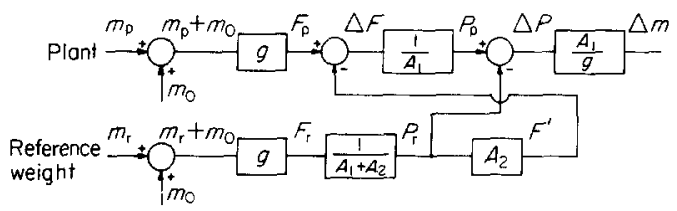

Fig. 5. Block diagram of the weighing system

on the disk on the plant side (right). Suppose the mass of the plant is in perfect balance with the reference weight, then the right servo will achieve equilibrium at a pressure $p_{\mathrm{p}}=p_{\mathrm{r}}$. By increasing (or decreasing) the mass of the plant only, the pressure $p_{\mathrm{p}}$ will be changed because $p_{\mathrm{r}}$ and hence $F^{\prime}$ will remain constant. A block diagram of the complete instrument is given in Fig. 5 . In this figure all dynamic terms are removed, which is only allowed when the moving parts are at rest. It can easily be seen that the change in mass, $\Delta m$ is given by

$$
\Delta m=m_{\mathrm{p}}-m_{\mathrm{r}}=\frac{A_{1} \Delta p}{g} .
$$

The sensitivity of the instrument depends only on (both) areas $A_{1}$. The gaps of the servo's should be kept in the linear range of about $5 \mu \mathrm{m}$; robust oil dampers (D) have therefore been provided against the possibility of any shock loading. Due to the almost symmetric construction, most temperature problems have been solved adequately (Appendix A3). Although there is no diaphragm in the servo (see Fig. 2 and Fig. 4), a force-free seal should be incorporated between the moving disk (C) and the housing. This has been provided by a thin $(23 \mu \mathrm{m})$ polyester 
membrane (E) with negligible stiffness (Appendix A4). Another advantage is that there is no electrical contact between the moving parts and the housing; this is necessary because electrical contact is used to indicate when friction may be present due to mechanical contact (Appendix A5).

\section{Laboratory Tests}

\subsection{Accuracy}

During development, all critical elements were tested. In this section, only the results of the complete set up are discussed. The pressure signal is transformed into an electrical signal $(372 \mu \mathrm{V} / \mathrm{g}$ by a transducer as described in Appendix A6 and digitized by a 6.5-digit measuring instrument (Fluke type $8502 \mathrm{~A}$ ) sampling at $200 \mathrm{~Hz}$. After $n$ samples a mean value $m_{n}$ is calculated, giving just one reading $\left(m_{n}\right)$ after each time interval of $n / 200 \mathrm{~s}$. For calibration purposes, we used $n=1024$ samples. When the samples contain normal distributed errors, the standard deviation $\sigma_{n}$ of this readings $\left(m_{n}\right)$ will be reduced, compared with a single sample $m_{1}$, by a factor $\sqrt{n}$. This has been verified experimentally. At constant load the standard deviation of $m_{n}$ has been obtained from six series of 40 readings each:

$$
\sigma_{n}^{2}=\sum_{i=1}^{40} \frac{\left[m_{n}(i)-\bar{m}_{n}\right]^{2}}{40-1}
$$

For the six different values of $n$, good agreement was found with the theoretical value $\sigma_{1} / \sqrt{ } n$ as shown in Table 1.

TABLE 1

The measured standard deviation $\sigma_{\mathrm{n}}$ of the readings can be approximated by $\sigma_{1} / \sqrt{ } \mathbf{n}$, with $\left(\sigma_{1}=250 \mathrm{mg}\right)$

\begin{tabular}{l|c|c|c}
\hline$n$ & $\begin{array}{c}\sigma_{n} \\
m g\end{array}$ & $\begin{array}{c}\sigma_{1} / \sqrt{ } n, \\
m g\end{array}$ & $\begin{array}{c}\text { Sampling time, } \\
s\end{array}$ \\
\hline 1 & 250 & 250 & 0.005 \\
$2^{7}$ & 20.2 & 22.0 & 0.6 \\
$2^{8}$ & 11.5 & 15.6 & 1.3 \\
$2^{9}$ & 11.9 & 11.0 & $2 \cdot 6$ \\
$2^{10}$ & $7 \cdot 3$ & 7.8 & $5 \cdot 1$ \\
$2^{11}$ & 6.4 & 5.5 & 10 \\
$2^{12}$ & 3.9 & 3.9 & 20 \\
\hline
\end{tabular}

Further, the instrument has been calibrated against a set weight. With $q$ series of $p$ points each, the standard deviation was calculated from

$$
\sigma_{n}^{2}=\sum_{i=1}^{p} \sum_{j=1}^{q} \frac{\left[m_{n}(i j)-\bar{m}_{n}(i)\right]^{2}}{p(q-1)} \text { with } \bar{m}_{n}(i)=\frac{1}{q} \sum_{j=1}^{q} m_{n}(i, j)
$$

This test was done for a constant value $n=2^{10}$. With $p=12$ and $q=5 \sigma_{\mathrm{n}}=0.04 \mathrm{~g}$ was found which, measured at variable load, is high in relation to Table $1(7.3 \mathrm{mg})$. The difference between both values shows clearly the effect of oil movement, by going quickly through the whole measuring range. The error curve is given in Fig. 6 , based on the values $\bar{m}_{\mathrm{n}}(i)$. The standard deviation of the given points a factor $\sqrt{5}$ lower compared with the value $\left(\sigma_{n}\right)$ as mentioned above. For different values of the counterweight $(0,50$ and $100 \mathrm{~kg})$ similar error curves have been found. This error curve is mainly caused by the differential pressure meter as shown in Appendix 6 . 


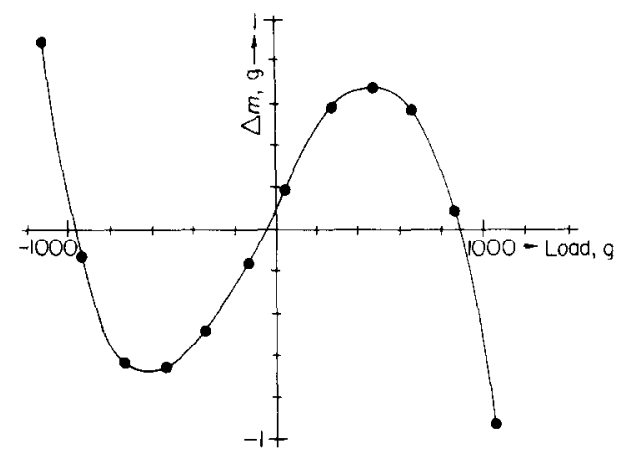

Fig. 6. Error curve of the complete set-up at a load of $50 \mathrm{~kg}$. The given points are deviations of the linear regression line. Standard deviation of the points $0.02 \mathrm{~g}$. Sample frequency $200 \mathrm{~Hz}$, sampling time $5 \mathrm{~s}$

\subsection{Line voltage}

The nominal line voltage $U=220 \mathrm{~V}$. The response to voltage deviations amounted to $\mathrm{d} m / \mathrm{d} U=-55 \mathrm{mg} / \mathrm{V}$ and so the line voltage was stabilized at $0 \cdot 1 \mathrm{~V}$.

\section{3. $\quad$ Air pressure}

The nominal air pressure on the bearings is $p=5$ bar. It was found that at zero load $\mathrm{d} m / \mathrm{d} p=-0.5 \mathrm{~g} / \mathrm{bar}$, at $50 \mathrm{~kg}$ load $-0.8 \mathrm{~g} / \mathrm{bar}$ and at full load $-2.1 \mathrm{~g} / \mathrm{bar}$. With a pressure regulator, the compressor ripple could be reduced to 0.01 bar, giving apparent mass errors of $20 \mathrm{mg}$ maximum which is in the same order as the standard deviation of the instrument under laboratory conditions.

\subsection{Temperature}

Most persistent are the thermal errors. Fig. 7 shows a daily periodicity in weight, in spite of a constant load. The source of this error was found to be located in the pressure transducer, particularly the membrane, as shown in Appendix 6. After keeping the transducer at constant temperature, no systematic thermal errors could be found. A special problem occurred due to an incorrect choice of materials for the air bearings. The temperature coefficient of the brass housing is about twice the value of the ferritic stainless steel shaft and this caused mechanical contact at temperatures lower than $+5^{\circ} \mathrm{C}$. This problem was solved by heating the instrument to about $30^{\circ} \mathrm{C}$

\subsection{Dynamic behaviour}

During the design calculations, the instrument was considered as a second order linear massspring system with the flapper-nozzle system (Fig. 2) as a spring. From the spring constant, which was measured under equilibrium conditions (Fig. 3), the damping construction has been designed and dimensioned. However, in laboratory tests, the actual (dynamic) stiffness of the "spring" was found to be much lower and moreover not constant (dependent on load). Using more viscous oil $\left(\eta=0.3 \mathrm{Ns} / \mathrm{m}^{2}\right)$ it was found that sufficient damping could be obtained. Fig. 8 shows the response of the system to a step function of $50 \mathrm{~g}$. These steps were made with the instrument balanced at a load of respectively 0,50 and $100 \mathrm{~kg}$. With steps of $500 \mathrm{~g}$, similar results were obtained. From these responses natural frequencies and damping constants were calculated as given in Table 2 .

\subsection{Human transpiration}

To demonstrate robustness, a chair was mounted on the lysimeter to measure human transpiration. For a very fit student (minimum clothing), a value of $5.2 \mathrm{~g} / \mathrm{min}$ was measured following a $2000 \mathrm{~m}$ run, whereas with a relaxed (older) person only $0.5 \mathrm{~g} / \mathrm{min}$ was found (standard deviation $0.1 \mathrm{~g} / \mathrm{min}$ ). 


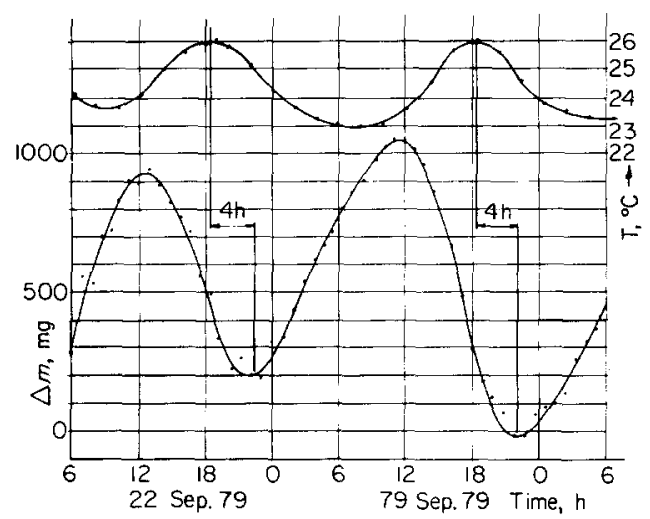

Fig. 7. Apparent weight deviations due to differences in room temperature

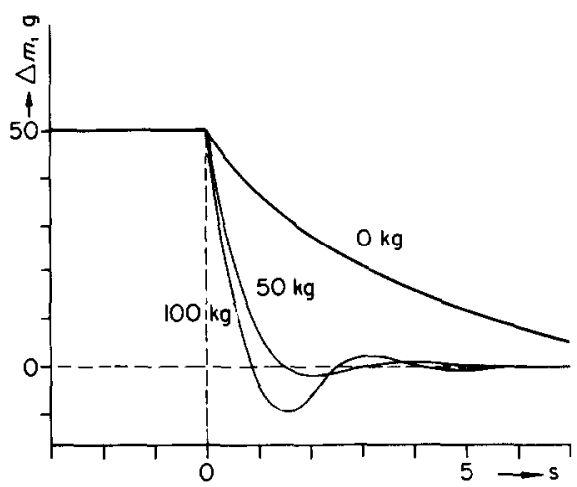

Fig. 8. Step response of the lysimeter

TABLE 2

Natural frequencies $\omega_{o}$ and damping constants $\boldsymbol{F}$ obtained from step functions of 50 and

$500 \mathrm{~g}$

\begin{tabular}{l|c|c}
\hline $\begin{array}{l}\text { load, } \\
k g\end{array}$ & $\beta$ & $\begin{array}{c}\omega_{0}, \\
\mathrm{rad} / \mathrm{s}\end{array}$ \\
\hline 50 & 0.85 & 1.79 \\
75 & 0.60 & 0.62 \\
100 & 0.47 & 0.51 \\
\hline
\end{tabular}

\section{Greenhouse experiments}

After laboratory tests, the lysimeter was used at the Naaldwijk Crops Research Experiment Station in a climate control experiment and then at the Institute of Agricultural Engineering (IMAG) Wageningen. Here, the lysimeter was incorporated in an extensive experimental research programme, aimed at obtaining data on the short term energy balance of a greenhouse tomato crop growing under commercial conditions. 


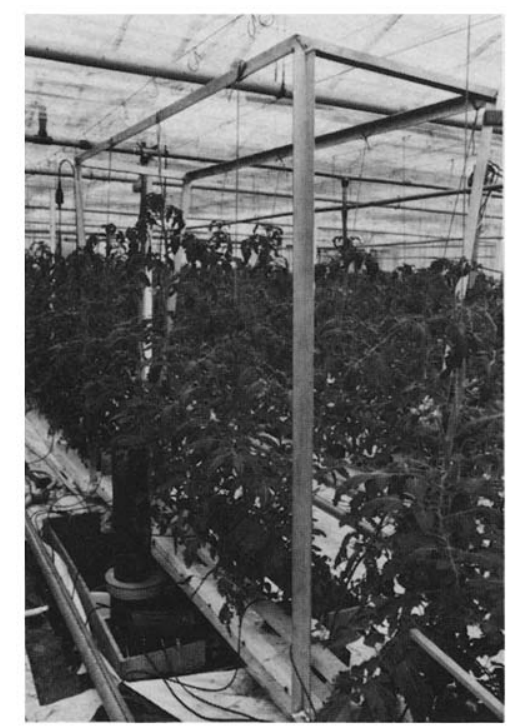

Fig. 9. The lysimeter in agricultural research. The electronic instrumentation is in a caravan outside the greenhouse

During two winter seasons, a tomato crop was grown in the greenhouse have a plant density of $2 / \mathrm{m}^{2}$ on rockwool mats. The lysimeter was placed in the centre of the greenouse, in a pit dug in the soil. The weighed plants were grown on an aluminium tray, which also supported a high frame used to train the plants (Fig. 9). Trays were constructed for four, six or eight plants, corresponding to a 2,3 or $4 \mathrm{~m}^{2}$ greenhouse area respectively. The soil was covered so that no evaporation could take place. Rockwool temperature on the tray and elsewhere in the crop rows did not differ significantly. The pressure sensor and signal processor, as well as the data logger, were situated in a caravan outside the greenhouse, at a distance of about $30 \mathrm{~m}$ from the lysimeter. Digital filtering reduced noise and a microprocessor calculated the weight and its derivative in desired time intervals of 1 to $10 \mathrm{~min}$. Both weight and ET could be plotted directly, as a function of time. Growth, leaf area and productivity of the plants growing on the tray were constantly checked and no important disparity was ever found relative to the surrounding crop.

\section{Results}

During both seasons, the lysimeter was checked frequently by adding small weights ( 2 to $100 \mathrm{~g}$ ), to the measuring side, at different loads on both sides (up to $100 \mathrm{~kg}$ ). No significant deviation from the initial calibration value $(372 \mu \mathrm{V} / \mathrm{g})$ was found. The next point of consideration was the limitation of the accuracy of the lysimeter due to air movement in the greenhouse. From outdoor precision lysimetry ${ }^{13,13}$ it is known that this can be the limiting factor. An estimate of the apparent variations in mass $\Delta m$, because of fluctuations $\Delta v$ in air velocity is given by

$$
\Delta m=0 \cdot 5 f_{\mathrm{d}} \frac{A \rho}{g}\left[(v+\Delta v)^{2}-v^{2}\right] .
$$

Since the air movement in the greenhouse fluctuates with an amplitude (as observed with hot bulb anemometers) of $\pm 0.01 \mathrm{~m} / \mathrm{s}$ around a value of circa $0.1 \mathrm{~m} / \mathrm{s}$, Eqn (5) yields about $\Delta m= \pm 0.3 \mathrm{~g}$. Thus, in the greenhouse set-up, the factor which limits accuracy is, indeed, air movement, when these calculations are compared with the instruments sensitivity. This is well illustrated by an experiment in which nightime ET was observed as a function of long wave radiation intensity, a set of four lamps ( $150 \mathrm{~W}$ each) was switched on and off around the crop on the 


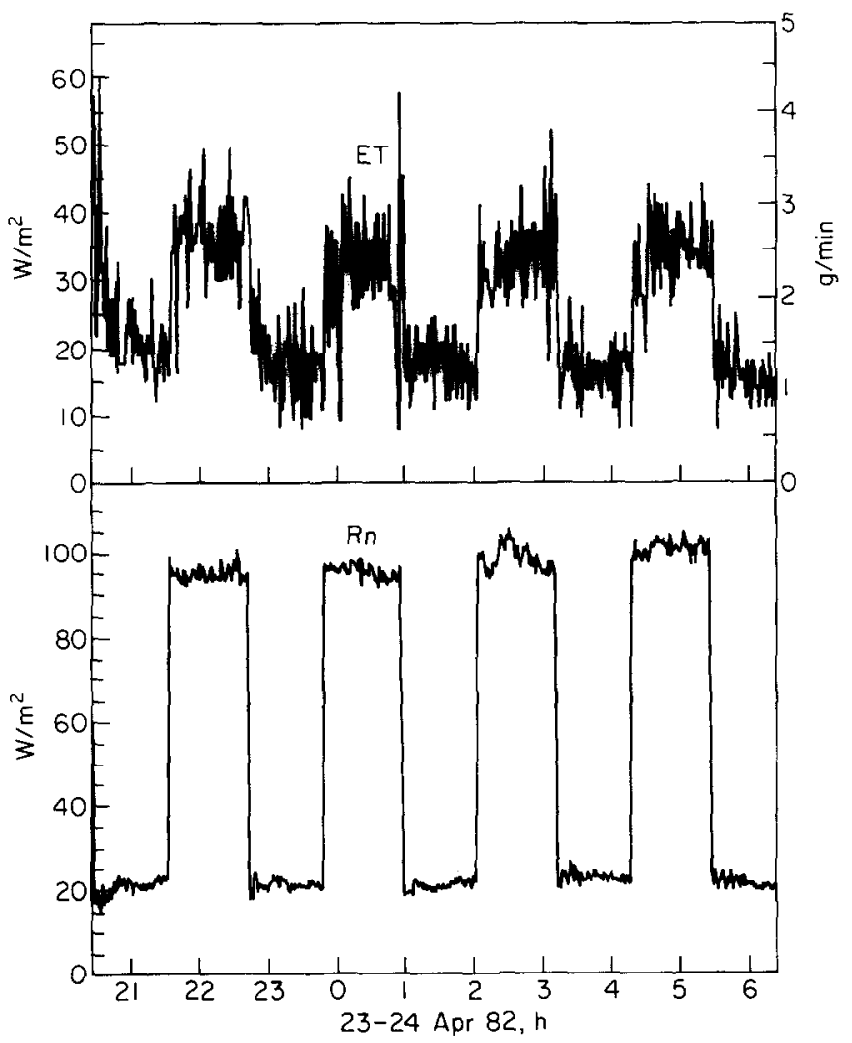

Fig. 10. Response of transpiration rate (ET) of tomatoes measured by the lysimeter, in relation to net periodic radiation $\left(R_{n}\right)$

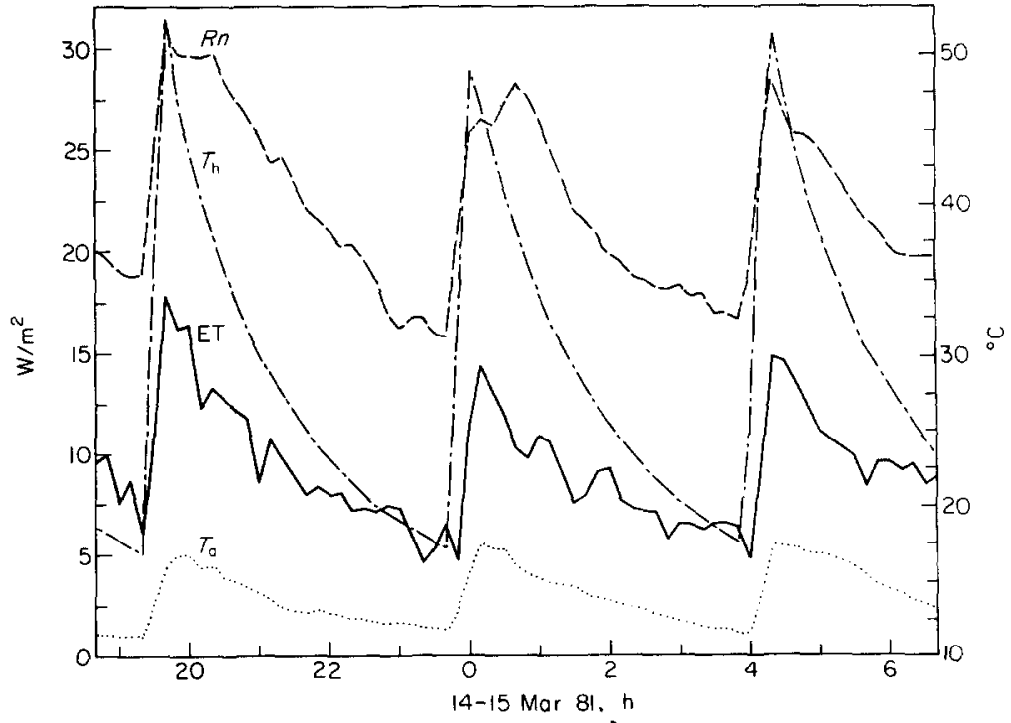

Fig. 11. Response of transpiration rate (ET) of tomatoes to heating pipe temperature $\left(T_{n}\right)$. Resulting variations of the net radiation $\left(R_{n}\right)$ above the canopy (absolute value) and of the inside air temperature $\left(T_{a}\right)$ are also shown. (There were four plants on the lysimeter, with a scanning interval of $10 \mathrm{~min}$ ) 


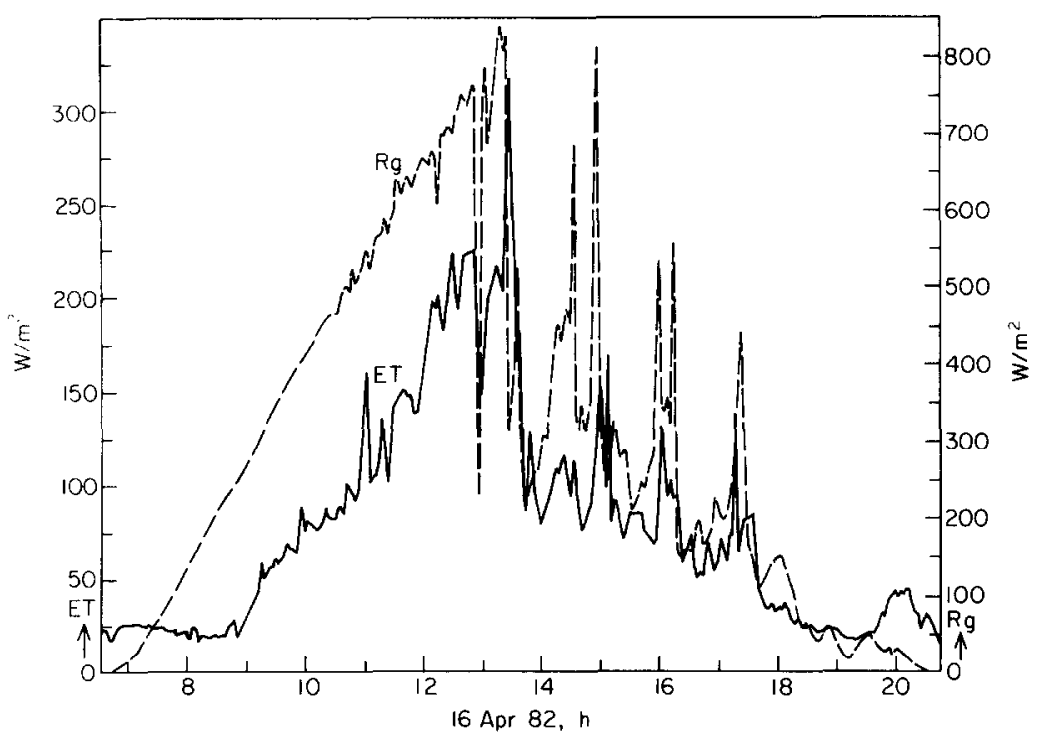

Fig. 12. Response of transpiration rate $(E T)$ of tomatoes to global solar radiation $\left(R_{g}\right)$. (There were six plants on the lysimeter, with a scanning interval of $3 \mathrm{~min}$ )

lysimeter (six plants) for 2 hours at a time. Fig. 10 shows the variation in net radiation (bottom) as measured at the lysimeter and (top) the corresponding ET, with 1 min intervals. On the hourly average values of $1.25 \mathrm{~g} / \mathrm{min}$ with lights off or $2.45 \mathrm{~g} / \mathrm{min}$ with lights on, a variation can be observed of about $\pm 0.3 \mathrm{~g} / \mathrm{min}$ which is in good agreement with the value predicted by eqn (5).

Another figure showing the capability of the instrument is Fig. 11, in which the response of ET to varying heating pipe temperatures at night is shown. Together with the variations in pipe temperature, the corresponding variations in net radiation above the canopy (absolute values) and the inside air temperature are also shown. There is a striking correspondence in the variation of the above quantities measured. The superimposed variations in ET are possibly due to air movement fluctuations, as discussed above. The response to fluctuating global incoming radiation is illustrated in Fig. 12. The pronounced maxima and minima of both solar radiation and ET show a clear correspondence. The ratio between ET and irradiation is 0.65 , which is in close agreement with published data for greenhouse tomatotes for this season. ${ }^{11,16,27,28}$

\section{Conclusions}

The developed lysimeter has proved to be a very sensitive instrument, able to detect weight differences below $0.1 \mathrm{~g}$, and operating very well in a greenhouse environment over a period of 3 years. The apparent mass fluctuations due to air movement are in the order of magnitude of $0.3 \mathrm{~g}$ with a time scale of several minutes. This problem is inherent in the use of accurate weighing lysimeter installations. Small variations in ET, even around the very low night time level were measured and responses on a $1 \mathrm{~min}$ time scale to various influences could be shown. Evaluation of this type of measurement is the subject of present studies.

\section{Acknowledgements}

A financial grant from the Dutch ministry of Agricultural to one of us (C.S.) is gratefully acknowledged. The success of the development is due to students of the Twente University of Technology, J. A. van Eijden (general design), J. G. Met (development pressure meter) and E. Toorn (construction and testing). 
Experimental work was carried out by F. Dormans, R. van Lakwijk, F. Maas, A. van't Ooster and J. E. Reinders who are assisted by Ing. D. P. van den Akker, all of the Agricultual University of Wageningen. Mr W. Joustra (Twente) has given special attention to the maintenance of the lysimeter.

\section{REFERENCES}

1 Stanghellini, C. Estimation of energy requirement for evapotranspiration in greenhouses. Acta Hort., 1981 $115693-699$

2 Meijer, J. Reduction of heat losses from greenhouses by means of internal blinds with low thermal emissivity. J. agric. Engng Res., 198025 381-390

3 Seginer, J.; Levav, H. Models as tools in greenhouse climate design. Technion Research and Development Foundation, Research no. 150-085. First annual report, Haifa, Israel

4 Bot, G. Greenhouse climate: From physical processes to a dynamic model. Ph.D. Thesis. Agr. Un. Wageningen, 1983

5 Van Bavel, C. H. M.; Damagnez, J.; Sadler, E. J. The fluid roof solar greenhouse: Energy budget analyses by simulation. Agric. Met., $19802361-76$

6 Udink ten Cate, A. J.; Bot, G. P. A.; van Dixhoorn, J. J. Computer control of greenhouse climates. Acta Hort., $87265-272$

7 Udink ten Cate, A. J. Modelling and (adaptive) control of greenhouse climates. Ph.D. Thesis. Agr. Un. Wageningen, 1983

${ }^{8}$ Hashimoto, Y. Computer control of short term plant growth by monitoring leaf temperature. Acta Hort., 106 139-146

- Hopmans, P. A. M. In-situ plant water relations monitoring for greenhouse climate control with computers. Acta Hort., 119 137-145

10 Schurer, K.; Griffioen, H.; Kornet, J. G.; Visscher, G. I. W. Measurement of the rate of water flow in plants. Neth. J. agric. Sci., 1979 27(2) 136-141

1 De Graaf, R. Onderzoek naar de waterhuishouding in het bijzonder het waterverbruik bij een teelt van stooktomaten in 1977. Internal Report Proefstation voor Tuinbouw onder Glas, Naaldwijk, 197836 34p (Dutch)

12 Pruitt, W. O.; Angus, D. E. Large weighing lysimeter for measuring evapotranspiration. Trans. ASAE, $1960,213-15$

13 Van Bavel, C. H. M.; Myers, L. E. An automatic weighing lysimeter. Agric. Engng, 1962 580-583, 586-588

14 Lawrence, F. J.; Goddard, W. B. A water-level measuring system for determining evapotranspiration rates from a floating lysimeter. J. appl. Met., 19676 (3), p 489-492

15 Ritchie, J. T.; Burnett, E. A precision weighing lysimeter for row crop water use studies. Agron. J., 196860 545-549

16 Morris, L. G.; Neale, F. E.; Postlethwaite, J. D. The transpiration of glasshouse crops, and its relationship to the incoming solar radiation. J. agric. Engng Res., 19572 111-122

17 Lake, J. V.; Postlethwaite, J. D.; Slack, G.; Edwards, R. J. Seasonal variations in the transpiration of glasshouse plants. Agric. Met., $19663187-196$

18 Hanan, J. J.; Huffsmith, R. Weighable lysimeter and recording system used in greenhouse studies. J. Am. Soc. hort. Sci., $196791691-698$

19 Hand, D. W. Electrically-weighed lysimeter of measuring evaporation rates. Agric. Met. 1968 5 269-282

${ }^{20}$ White, J. W.; Vaslcik, E. M. A recording evaporation gauge lysimeter for plants in small containers. Hort. Sci., 1972 $3243-244$

21 Stanhill, G.; Scholte Albers, J. Solar radiation and water loss from glasshouse roses. J. Am. Soc. hort. Sci., 197499 (2) $107-110$

22 De Graaf, R.; van de Ende, J. Transpiration and evapotranspiration of glasshouse crops. Acta Hort., 1981 $119147-158$

${ }^{23}$ Tegelaar, P.; van der Wal, A. F. A simple and accurate balance for the continuous measuring and recording of (evapo) transpiration of plants in indoor experiments. Neth. J. P1. Path., $19748077-84$

24 Doebelin, E. O. Measurement Systems, Application and Design. New York: McGraw-Hill Inc., 1975

25 Profos, P. Handbuch der Industriellen Messtechnik. Essen: Vukan-Verlag, 1978 (German)

26 Hofman, D. Handbuch Messtechnik und Qaulitätssicherung, Berlin: VEB Verlag Technik, 1979 (German)

27 Stanhill, G. An irrigation gauge for commercial use in field and glasshouse practice. J. agric. Engng Res., $19583292-298$ 
${ }^{28}$ Rothwell, J. B.; Jones, D. A. G. The water requirements of tomatoes in relation to solar radiation. Exp Hort., $1961525-30$

29 Wilcock, D. F. et al. Design of Gasbearings. New York: MTI, 1967

so Roark, R. .J. Formules for stress and strain. New York: McGraw-Hill, 1975

31 Timoshenko, S. P.; Woinowsky-Krieger, S. Theory of plates and shells. New York: McGraw-Hill, 1959

\section{Appendix 1}

Flapper nozzle system

A force $F$ causes a diaphragm deflection $x$ which, in turn, causes the pressure $p$ to increase since the nozzle is more restricted (Fig. 2). This increase in pressure, acting on area $A$ produces an effective force $F_{\mathrm{p}}$ which tends to return the diaphragm to its former position. For any constant $F$, the system will come to equilibrium with a specific nozzle opening and corresponding pressure $p$ which is given by ${ }^{24}$

$$
p=\frac{F}{\mathrm{~K}_{\mathrm{d}} / K_{\mathrm{n}}+A},
$$

where $K_{\mathrm{d}}=\mathrm{d} F / \mathrm{d} x$ is the stiffness of the diaphragm and $K_{\mathrm{n}}=\mathrm{d} p / \mathrm{d} x$ is the nozzle constant. In our modified design (Fig. 2, right) the function of the restriction is realized by the orifices of the air bearings, while since there is no diaphragm the constant $K_{\mathrm{d}}=0$ reduces Eqn (A1) to $p=F / A$ which images a perfect transducer. Later we will see that other construction elements cause a small value of $K_{\mathrm{d}}$. This (modified) flapper-nozzle system, which is a critical part of the design has been tested extensively. It is not only of interest to know $K_{\mathrm{n}}$ for different configurations, but also the effective area $A$ should be determined experimentally, because the force on the rim (width $w$ ) is a function of the flow conditions over the rim. We found $A\left(20 \mathrm{~cm}^{2}\right)$ to be nearly constant (variations $<5 \cdot 10^{-5}$ ) for $D=60, d=33$ and $w=0.7 \mathrm{~mm}$ at a flow rate of $0.05 \mathrm{l} / \mathrm{s}$, which is kept almost constant by the restrictions in the air bearings.

\section{Appendix 2}

Air bearings

The air bearings are designed in accordance with the gas bearings design rules ${ }^{29}$ to carry the moment caused by an axial load at $10 \mathrm{~cm}$ eccentricity. This has been realized with inherent compensated types (for maximum stiffness) with a radial clearance of $15 \mu \mathrm{m}$ and an orifice diameter of $0.3 \mathrm{~mm}$. At maximum load, the calculated (relative) eccentricity is 0.4 , causing a minimum film thickness of $9 \mu \mathrm{m}$. The shafts are made of a ferritic-martensitic steel (DIN 4104, AISI 430F) with low thermal expansion.

\section{Appendix 3}

Thermal expansion of the instrument

Assuming the whole instrument is at the same temperature, the temperature coefficient using Eqn (1) and Eqn (2) is found to be

$$
\frac{\mathrm{d} \Delta m}{\mathrm{~d} T}=\frac{\pi}{2}\left[D^{2} a_{\mathrm{D}}-(d-w)^{2} a_{\mathrm{d}}\right] \frac{\Delta p}{g} .
$$

As can easily be seen, this value can be made zero using materials with different coefficients of expansion $\left(a_{\mathrm{D}}\right.$ and $a_{\mathrm{d}}$ in which the indices refer to the diameters of the different parts as shown in Fig. 2). Nevertheless, for the instrument described here, materials were used with $a_{\mathrm{D}}=a_{\mathrm{d}}=10 \mu \mathrm{m} / \mathrm{m} . \mathrm{K}$. For this reason it is necessary to maintain a constant temperature. 


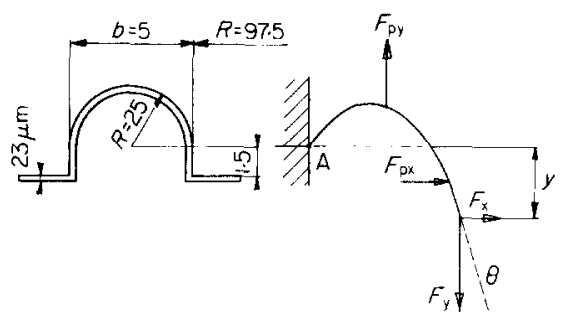

Fig. A1. Membrane; dimensions (left) and forces on a small section d (right)

\section{Appendix 4}

\section{Membranes}

A difficult task was to define the membranes (Fig. 4, part E). They should combine minimum stiffness and low hysteresis. These Membranes (Fig. Al) have been formed at $190^{\circ} \mathrm{C}$ in a vacuum mould from a $23 \mu \mathrm{m}$ thick polyester film (Melinex). Supposing the membrane has no bending, stiffness, which will be discussed later, then the pressure $p$ will cause an axial force $F$ on the moving part which is found to be

$$
F_{y}=\frac{\pi R p\left(b^{2}+y^{2}\right)}{b-y \tan \theta} \text {. }
$$

Under the condition that $y \tan \theta \ll b$ and $y^{2} \ll b^{2}$ the stiffness is found to be

$$
K=\frac{\partial F}{\partial \mathrm{y}}=\pi R p\left(2 \frac{y}{b}+\tan \theta\right) \text {. }
$$

This can be related to mass since the total force $\mathrm{mg}=\pi R p(r+b)$ which gives

$$
\Delta m=\frac{m}{R+b}\left(2 \frac{y}{b}+\tan \theta\right) \Delta y .
$$

With $\Delta y \leqslant 10 \mu \mathrm{m}$ (Fig. 3), $m=116 \mathrm{~kg}$ (full load +dead weight), $y \leqslant 0.2 \mathrm{~mm}$ and $\tan \theta \leqslant 0.05$ we get $\Delta m \leqslant 1.5 \mathrm{~g}$, which is $0.05 \%$ of a measuring range of $3 \mathrm{~kg}$.

\section{Appendix 5}

\section{Friction and electrical contact}

When there is friction anywhere between moving parts of the instrument, the readings will be unreliable. Friction is always combined with mechanical contact and, using conductive materials, also by electrical contact. During operation, the moving parts of the lysimeter should be electrically isolated from the fixed parts by an air film (bearings and flapper-nozzle), a polyester membrane and an oil film (damper). This operation condition is checked by measuring the electrical resistance between fixed and moving parts. When the resistance falls below $100 \mathrm{k} \Omega$ the control lamps are switched from green (safe) to red (warning). To avoid sparking in the small bearing gap, the test voltage is kept below $1 \mathrm{~V}$. When using moist air for the bearings, this is also signalled by the red lamps. As encountered in greenhouse operations, plants which touch each other can cause a red signal too. This can be avoided, by placing the pot on isolating foil.

\section{Appendix 6}

\section{Pressure transducer}

To measure $0 \cdot 1 \mathrm{~g}$ at a range of $3 \mathrm{~kg}$, a pressure transducer with an accuracy of $3 \cdot 10^{-5}$ is required. For laboratory experiments and calibration purposes, a water column with optical 


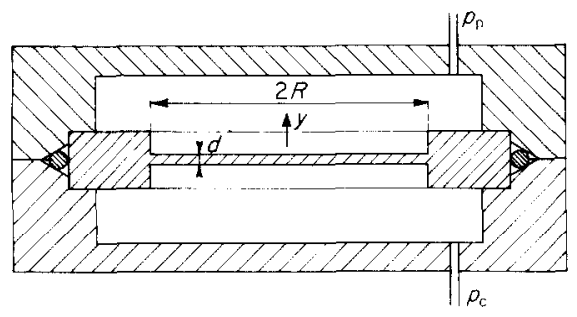

Fig. A2. Pressure meter membrane (material: $0 \cdot 36 \mathrm{C} 1.4 \mathrm{Cr} 1.4 \mathrm{Ni} 0 \cdot 2 \mathrm{Mo}$ ). The outer ring keeps the flat membrane under constant stress

readings to $0.01 \mathrm{~mm}$ (corresponding to $20 \mathrm{mg}$ ) was used. For use in the field, a special pressure transducer was designed (there was no commercial instrument which met our requirements). A flat pre-stressed creepfree membrane (Fig. A2) is used combined with a commercial inductive displacement transducer (TESA). For a flat membrane, the central displacement $y$ is given by Roark $^{30}$ as

$$
y=\frac{3}{16} \frac{\Delta p R^{4}\left(1-v^{2}\right)}{E d^{3}} \frac{1}{1+0 \cdot 488 y^{2} / d^{2}},
$$

while the maximum tension in the material is given by Timoshenko and Woinowsky-Krieger ${ }^{31}$

$$
\sigma_{\max }=\frac{3 \Delta p R^{2}}{4 d^{2}}
$$

This was designed for a pressure difference $\Delta p=10^{4} \mathrm{~N} / \mathrm{m}^{2}$, corresponding to an apparent mass difference of $2 \mathrm{~kg}$ with $R=45$ and $d=0.7 \mathrm{~mm}$ (Fig. A2) giving $y_{\max }=100 \mu \mathrm{m}$, which can be measured, with special care, to a relative accuracy of $3 \cdot 10^{-5}$. Because $\triangle p$ can be either positive or negative, the total range is $4 \mathrm{~kg}$. From Eqn (A6), the temperature coefficient of the membrane is

$$
\frac{1}{y} \frac{\mathrm{d} y}{\mathrm{~d} T}=\frac{1}{L} \frac{\mathrm{d} L}{\mathrm{~d} T}-\frac{1}{E} \frac{\mathrm{d} E}{\mathrm{~d} T}=a-\lambda .
$$

The thermal error curve (Fig. 6) was measured when the transducer was insulated in polyurethane foam and consequently acts, as a first order thermal system with a time constant $\tau=8.1 \mathrm{~h}$. With the daily frequency $\omega=0.26 \mathrm{rad} / \mathrm{h}$, the phase shift will be $4.3 \mathrm{~h}$, while the amplitude of the thermal wave is reduced by a factor $1 / \sqrt{1+(\omega \tau)^{2}}=0 \cdot 4$. With a membrane load of $2.5 \mathrm{~kg}$ (Fig. 3), the daily thermal wave with height $3^{\circ} \mathrm{C}$ can be translated (Eqn A8) to mass differences of about $1 \mathrm{~g}$, which is, like the phase shift, completely in accordance with the measured values.

Because for the steel transducer membrane $a \simeq 10^{-5} / \mathrm{K}$ and $\lambda \simeq-3 \cdot 10^{-4} / \mathrm{K}$, a temperature stabilization within $0 \cdot 1 \mathrm{~K}$ is necessary. With a resistance heater outside the foam, controlled by a simple switching thermostate, $\Delta T<0.01 \mathrm{~K}$ was reached, inside the foam. A typical calibration curve of this pressure meter is given in Fig. A3. According to the last term of Eqn (A6), a third power error curve is found. Due to the range of our special reference water column (provided with a laser interferometer) the instrument could be calibrated only from -1200 to $1200 \mathrm{~g}$. For easy comparison, the results have been translated to a mass scale, while only deviations from the best fitting linear line are shown. This line, which has a slope of $372 \mathrm{mV} / \mathrm{kg}$, has been determined by the method of linear regression analysis. A complication is caused by the non-symmetric 


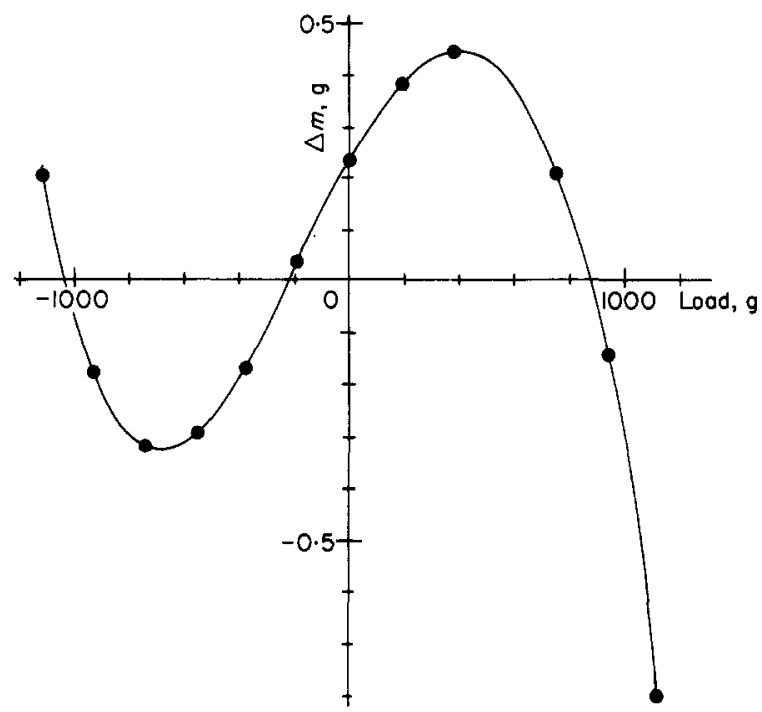

Fig. A3. The pressure meter shows an asymmetric error curve due to initial deformation. Standard deviation of the points $0.04 \mathrm{~g}$

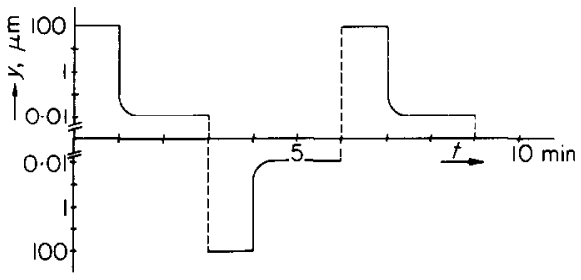

Fig. A4. Hysteresis of the pressure meter

shape which could only be explained by the membrane not being flat at $\Delta p=0$. It was afterwards verified that the membrane was $10 \mu \mathrm{m}$ spherical (10\% of the range). Fortunately, this calibration curve has been proved to be very reproducible (standard deviation of the points $0.04 \mathrm{~g}$ by measurement against the water column). Note that the standard deviation of the total set up $(0.02 \mathrm{~g}$ as given in Section 3.1) is significantly better due to the lack of a water column in this case.

A hysteresis of $10^{-4}$ after $1 \mathrm{~min}$ full load (Fig. A4) and $2 \cdot 10^{-4}$ after $15 \mathrm{~min}$ full load was unexpected. Both values were measured $2 \mathrm{~min}$ after unloading (after $0.5 \mathrm{~min}$, the signal is stable). From the material specification, a permanent deformation of $0.2 \%$ was given at $\sigma=77 \times 10^{7} \mathrm{~N} / \mathrm{m}^{2}$. Thus, it was surprising to find a value of $0.01 \%$ after $1 \mathrm{~min}$ at $\sigma=3 \times 10^{7} \mathrm{~N} / \mathrm{m}^{2}$. 